\title{
Mixed-Mode Fatigue Crack Growth in FM73 Bonded Joints
}

\author{
Hafiz TA ${ }^{\mathrm{a}}$, Abdel-Wahab MM${ }^{\mathrm{b}}$, Crocombe $\mathrm{AD}^{\mathrm{a}, *}$ and Smith $\mathbf{P A}^{\mathrm{a}}$ \\ ${ }^{a}$ Division of Mechanical, Medical and Aerospace (MMA) Engineering, Faculty of \\ Engineering and Physical Sciences (FEPS), University of Surrey, Guildford, Surrey, GU2 \\ $7 \mathrm{XH}, \mathrm{UK}$.
}

${ }^{b}$ Department of Mechanical Construction and Production, Faculty of Engineering and Architecture, Ghent University, Technologiepark903, B-9052 Zwijnaarde, Belgium

*Corresponding author: Prof. Andrew D Crocombe

e-mail: A.Crocombe@surrey.ac.uk, T +44 (0)1483689194

\begin{abstract}
Fatigue tests have been carried out to investigate mixed mode fatigue crack growth behaviour in FM73 epoxy adhesive using Double Cantilever Beam (DCB) specimens. The DCB configuration used consisted of equal thickness mild steel adherends bonded with FM73 adhesive. The joints were tested under pure mode I and a range of fatigue mixed-mode conditions using a relatively simple, variable-mode loading fixture developed in previous work [1].
\end{abstract}

The fatigue testing was carried out, in displacement control, with an initial load ratio $(R)$ of 0.1. The fatigue load decreased as the fatigue crack grew and this load was recorded. Crack growth was monitored and measured using a video microscope. The results suggest that crack initiation in the test specimens is controlled by the mode I strain energy release rate, $G_{\mathrm{I}}$, component. The fatigue crack growth rates were characterised using a Paris law approach, from which it appears that the total strain energy release rate range, $\Delta G_{\text {Total, }}$ is a more dominant factor in controlling crack growth than the mode I component of strain energy release rate range, $\Delta G_{\mathrm{I}}$.For a quantitative description of the mixed-mode fatigue crack growth, generalised forms of the Paris relation are developed. 
Keywords: A: epoxy/epoxide, B Aluminium and alloys, C Fracture Mechanics, D Fatigue, Mixedmode loading, Paris law,

\section{Nomenclature}

$a=$ Crack length

$B=$ Width of the adherend

$C=$ Paris law coefficient

$c_{1}, c_{2}$ and $c_{3}=$ Paris law coefficient curve fitting parameters

$C_{\mathrm{I}}=$ Paris law coefficient based on $\Delta G_{\mathrm{I}}$

$C_{\text {Total }}=$ Paris law coefficient based on $\Delta G_{\text {Total }}$

$E=$ Tensile modulus of the adherend

$E_{a}{ }_{a}=$ Tensile modulus of the adhesive

$F=$ Load applied to the jig from the test machine

$F_{1}=$ Load acting on the upper adherend

$F_{2}=$ Load acting on the lower adherend

$G_{\max }=$ Maximum strain energy release rate

$G_{I}=$ Mode I contribution of strain energy release rate

$\Delta G_{\mathrm{I}}=$ Mode I contribution of strain energy release rate range

$G_{\text {II }}=$ Mode II contribution of strain energy release rate

$G_{\text {Total }}=$ Total (combination of $G_{\mathrm{I}}$ and $G_{\mathrm{II}}$ ) strain energy release rate

$\Delta G_{\text {Total }}=$ Total (combination of $\Delta G_{\mathrm{I}}$ and $\Delta G_{\mathrm{II}}$ ) strain energy release rate range

$h=$ Thickness of the adherend

$m=$ Paris law exponent

$M_{1}=$ Moment acting on the upper adherend

$M_{2}=$ Moment acting on the lower adherend

$m_{1}, m_{2}$ and $m_{3}=$ Paris law exponent curve fitting parameters

$M_{\mathrm{I}}=$ Mode I component of moment acting on the sample

$m_{\mathrm{I}}=$ Paris law exponent based on $\Delta G_{\mathrm{I}}$

$M_{\mathrm{II}}=$ Mode II component of moment acting on the sample

$m_{\text {Total }}=$ Paris law exponent based on $\Delta G_{\text {Total }}$

$S_{1}, S_{2}, S_{3}$ and $S_{4}=$ Distances between support points in the loading jig

$t=$ Thickness of the adhesive

$\vartheta=$ Poisson's ratio of the adherend 


\section{Introduction}

The use of adhesive bonding has become much more widespread in recent years. However, a particular issue with the integrity of adhesive joints is the presence of cracks and flaws in the as-manufactured adhesive bond-line. The presence of these defects, at least at some scale, appears inevitable and the propagation of such cracks/flaws has the potential to affect the service life of the adhesively bonded joints and even to cause catastrophic failure of bonded structures in service. Hence a better understanding of crack propagation behaviour under realistic types of combined (direct and shear stress components) service loading is an important aspect of evaluating the potential performance of adhesively bonded joints [1].

In the case of a joint experiencing only peel stresses, a Fracture Mechanics (FM) approach simply requires the evaluation of mode I crack driving force as a function of crack length in the joint and the knowledge of the mode I Fatigue Crack Growth (FCG) behaviour [2]. Many studies have been conducted [3-10] that demonstrate a sigmoidal relationship on a log-log plot between the cyclic fatigue crack growth rate $(\mathrm{d} a / \mathrm{d} M)$ and crack driving parameter, generally evaluated in terms of the strain energy release rate $(G)$ or related parameter. However, in structural applications of adhesive joints, it is appropriate to reduce the peel stresses (i.e. stresses perpendicular to the bondline) in favour of shear stresses to improve joint strength [9]. Most of the joint geometries used in practice are characterised by the combined presence of peel and shear stresses, hence experiencing mixed mode loading conditions at the crack tip. In a joint subject to both peel and shear stresses, the total strain energy release rate, mode I or mode II component or some combination thereof are possible parameters to characterise FCG behaviour [10].

Concerning the FCG properties, the majority of existing experiments have been performed under mode I conditions for which well-assessed procedures based on Double Cantilever Beam (DCB) or Tapered Double Cantilever Beam (TDCB) specimens already exist. Nevertheless, there is experimental evidence for bonded joints [10-12] that mixed mode ratio affects the FCG rate. To perform reliable predictions of fatigue lifetime and endurance limit, it is, therefore, desirable to have crack propagation data for a range of mixed mode loadings. The structure of the paper is as follows. In the next section, the test method used is discussed, together 
with closed-form analyses that enable the strain energy release rate components to be determined. The results from the test programme are then presented.. Paris plots for these data are presented in a conventional way. The results are discussed and compared with other studies in the literature.Following this the failure surfaces are considered and finally a mixed mode fatigue crack growth law presented

\section{Fatigue Test Method}

In the present work, a simple loading jig, as shown in Fig.1, was used as described in [1]. The jig allows fatigue testing of a DCB type specimen in pure mode I and over a wide range of mixed-mode ratios.

The mild steel DCB adherends (Fig. 2) were grit blasted, cleaned in acetone and then clamped with FM73 film adhesive inserted and bonded at an elevated temperature in an oven. Shims were used (see Fig 2) to control the adhesive thickness. This formed a natural bond end with no pre-crack. The cure cycle followed was in accordance with the data sheet from the adhesive manufacturer - a heating cycle up to $120^{\circ} \mathrm{C}$ in 30 minutes followed by a hold for 60 minutes and then leaving in the oven with door shut until the temperature reaches room temperature. After samples had been cured, they were stored in a desiccator and they were tested typically one to two days after manufacturing. The bonded joint manufacturing process, the quasi-static failure testing and the loading jig design and operation were described in more detail elsewhere [1]. The fatigue testing of the joints was carried out using the loading jig shown in Fig 1, mounted on a $20 \mathrm{kN}$ Instron 8511 fatigue testing machine, as seen in Fig. 3. Different mode mixities were obtained by using different pin positions in the loading jig. Calculation of mode I and mode II components of energy release rates $G_{\mathrm{I}}$ and $G_{\mathrm{II}}$, respectively was based on the method outlined by Williams [13]. This considered the general case of a cracked DCB with arms of unequal thickness, acted on by moments $M_{1}$ and $M_{2}$, but did not include the adhesive bondline thickness which has been shown to influence the fracture energy of the joint [4]. It has been shown using FEA that the method developed in [13] can underestimate energy release rate results by as much as $40 \%$ [14]. Therefore, a further term [15] was introduced to take this adhesive thickness 
effect into account. This approach is summarised by the relationships between the DCB loads $\left(F_{1}\right.$ and $\left.F_{2}\right)$ and $G_{I}$ and $G_{I I}$ as shown in Fig. 2; these expressions give good agreement with FEA results $[1,14]$ and were used in the present study.

In addition to the pure mode I test configuration, tests were carried out over a range of mode mixities $G_{\Pi} / G_{\mathrm{I}}$. The geometries used gave initial mode mixity ratios of 0.22 , $0.72,1.29$ and 6.62. The values are a function of crack length and they increase (slightly) as the crack grows during a fatigue test to final values of $0.24,0.74,1.32$ and 6.68 respectively.

After curing the DCB bonded joints, any excess adhesive was removed from the joint with abrasive paper and the bond-line was highlighted using diluted white typewriting corrector fluid to enable the crack tip to be identified more easily. The crack length was measured using a scale attached to the edge of the joint. A digital microscope enabled the crack length to be monitored with up to 200x magnification on the computer screen

Fatigue tests were run using the Instron software "Wave Matrix" [16]. The test procedure was as follows. A specimen was loaded to $70 \%$ of the quasi-static failure load and the corresponding value of maximum displacement was recorded. The specimen was then unloaded to the minimum load (using an initial load ratio $R=$ 0.1 , to obtain the corresponding minimum displacement. The fatigue test was then run in displacement control between these maximum and minimum values of displacement. By using displacement control the energy release rate decreases with crack length and allows a threshold value to be determined.The crack length was monitored throughout each test using in-situ video microscopy. For each test configuration, a minimum of three repeats were carried out.

The reduction in maximum load with fatigue cycles for a specimen with a nominal initial mode mixity of 0.72 (based on $G_{I I} / G_{\mathrm{I}}$,) tested under displacement control is shown in Fig. 4. Similar trends were observed for each specimen and for each mode ratio tested. It is apparent that the peak load remains essentially constant prior to the onset of crack growth. This occurred around 16000 cycles for the specimen illustrated in Fig 4.The point where the load starts to drop was recorded for each 
specimen as a measure of the number of cycles before the on-set of crack growth. Once the crack started to propagate there was a corresponding rapid decrease in maximum load.

This can be seen clearly in Fig. 5 where the load and crack length are shown as a function of number of fatigue cycles after the on-set of crack growth.

It is clear from Fig. 5 that initial crack growth was rapid but subsequently it reduced, while the corresponding load value fell steeply before levelling off. This is not surprising as under displacement control a reduced maximum load is required to keep the displacement constant because the compliance of the DCB increases with crack length. Similar trends for increase in crack length and decrease in maximum load in DCB bonded joints were also observed in [17].

A three-parameter exponential function was selected for curve fitting the crack growth data as shown in Eq. 1

$$
a=e^{(X+Y /(N+Z))}
$$

In Eq. 1, the terms $a$ and $N$ are the crack length and number of cycles, respectively. The three coefficients namely $X, Y$ and $Z$ were determined using curve fitting software and are $-2.56,-615.38$ and 576.70 respectively. A typical curve fit for the crack length data as a function of number of cycles is shown in Fig. 5.

It is conventional to try to represent FCG data using a Paris law type relationship i.e Eq. 2, which is well known to be applicable to metals and polymers [5]:

$$
\frac{d a}{d N}=C\left(G_{\max }\right)^{m}
$$

In Eq.2, the terms $C$ and $m$ are material constants known as the Paris law coefficient and exponent, respectively, $G_{\max }$ is the maximum strain energy release rate and $\mathrm{d} a / \mathrm{d} N$ is the FCG rate. The question is what form of the strain energy release rate parameter should be used to correlate data under mixed mode loading? In the present study data from different specimens are compared with each other on the basis of the mode I strain energy release rate range $\left(\Delta G_{I}\right)$ and on the basis of the 
total strain energy release rate range $\left(\Delta G_{\text {Total }}\right)$ as appropriate. Finally a more general form of the Paris law is developed, appropriate to mixed mode loading.

\section{Results and Discussion}

The main focus of the results and the subsequent analysis are the fatigue crack growth data and the corresponding fracture surfaces. Before considering these fatigue crack initiation is discussed.

\subsection{Fatigue Crack Initiation}

Three different configurations are available in the jig (Fig.1) to achieve a mode ratio of 0.72 . This feature was used to assess the self-consistency of the test setup. The 3 configurations are a) $S_{1}=0$ and $S_{2}=200$ and pinning the support at point $C$, b) $S_{1}=200$ and $S_{2}=0$ and pinning the support at point $C$ and c) $S_{1}=0$ and $S_{2}=200$ and pinning the support at point D (see [1] for more details). Nine specimens are shown at a mode mixity of 0.72 , which arise from testing three specimens at each of the three jig arrangements giving rise to this level of mode mixity. Three or four specimens were tested at each of the other mode mixities. It should be recalled that each of these test specimens were tested with an initial maximum fatigue load of $70 \%$ of the corresponding mean quasi-static strength. This corresponds to different strain energy release rate values for each mode mixity. Fig. 6 shows the average data for each of the 5 mode ratios, illustrating the relationship between the number of cycles to crack initiation in the as-cast joint (having no pre-crack) and the mode I and total strain energy release rates. These data suggest that for these specimens the number of cycles for crack initiation for the as cast joint correlates with the mode I component of the strain energy release rate: as the mode I value decreases, there is a greater number of cycles required for propagation of the crack in the as manufactured specimen.

\subsection{Fatigue Crack Propagation}

In this section, the results from the fatigue crack propagation tests over the range of mode mixities are presented. Plots of da/d $N$ against $\Delta G_{\mathrm{I}}$ and $\Delta G_{\text {Total }}$ are both shown to explore the effect of these different fracture mechanics parameters 
Fig. 7 compares all the FCG results for the 3 configurations that produce a modemixity ratio of 0.72 , plotting $\log \mathrm{d} a / \mathrm{d} N$ against $\log G_{\text {Imax. }}$. Refer to section 3.1 for details of these 3 configurations. Not only do the data more or less appear to superpose, which builds confidence in the use of the jig for fatigue testing, but the overall scatter in the fatigue crack growth rate of about one decade in crack growth rate at any strain energy release rate is reasonable when testing polymers, such as this adhesive, in fatigue [18].

Fig. 8 shows the FCG results for the full range of mode-mixities tested as a plot of $\log \mathrm{da} / \mathrm{d} N$ against $\log \Delta \mathrm{G}_{\mathrm{I}}$. Generally there is good consistency for a given mode ratio. In most cases, the mode of failure was cohesive within the adhesive and most of the scatter within a mode occurs if the failure surface shows some degree of apparent interfacial failure (giving rise to slightly faster FCG rates).

It is clear that as mode II contribution increased (or mode I contribution decreased) the data moved consistently to the left (i.e. FCG increasing with increasing mode II component of loading). This suggests that the mode II component has a significant influence on the crack growth rate which seems entirely reasonable. Some of the data sets appear to show a "shoulder" on the da/d $N-\Delta G$ plot. This phenomenon may be attributed to visco-elastic effects. In [15] a higher slope at low frequencies was identified with lower temperatures at the crack tip, giving more brittle behaviour compared to the higher frequency values. In the current work the initial strain energy release rates are high, which may cause a rise in temperature resulting in softened behaviour of the material at the crack tip. Another possibility is that the transition may be associated with the development of crack propagation at the carrier-adhesive interface. The microscopy suggests that this may be a preferred location for the crack path as will be seen in Figs 11 and 12 later. Further work would be necessary to investigate this.

Fig. 9 shows the FCG results for the full range of mode-mixities, presented as a plot of log da/dN against $\log \Delta G_{\text {Total }}$, where the total strain energy release rate, $\Delta G_{\text {Total, }}$, is $\Delta\left(G_{I}+G_{I I}\right)$. It is clear that this parameter $\left(\Delta G_{\text {Total }}\right)$ correlates the data much better than $\Delta G_{\mathrm{I}}$ (compare the spread of the data in Figs. 8 and 9). When the data are plotted in this way, it appears that, for a given $\Delta G_{\text {Total, }}$, the crack growth rate is a little lower for the mode mixities which are more mode I dominant. It may be that this is 
associated with different extents of crack tip plasticity for a given $\Delta G_{\text {Total }}$ with different mode mixities. In particular it could be that the plastic zone extends further from the crack tip with an increasing mode II contribution, as has been noted by two of the authors in earlier work [10]. This would potentially give larger crack growth rates.

Where data are available, there is reasonable agreement between the current results and those obtained in the literature for the FM73 adhesive system [19-21], see Fig. 10. The available data is almost all mode I fatigue crack growth but there are data for one mixed mode ratio. $\Delta G_{\mathrm{I}}$ has been selected for comparison purposes as there is no information available for $\Delta G_{\text {Total }}$ in the case of the mixed mode data [19] i.e. they plotted FCG only against $\Delta G_{\mathrm{I}}$. This correlation would suggest that the more extensive dataset developed in this work is reliable.

\subsection{Characterisation of Failure Surfaces}

Visual inspection indicated that fracture propagated within the FM73 adhesive (i.e. a cohesive type of propagation) for most of the cases. In order to examine the fracture surfaces in greater detail, samples were prepared for SEM examination by coating the fracture surfaces with a layer of gold approximately $8 \mathrm{~nm}$ thick. The DCB specimens were then examined using a Hitachi S3200N scanning electron microscope (SEM). A $20 \mathrm{kV}$ electron beam was used for scanning to minimise any charging effects. Fig. 11 and 12 show images for pure mode I and mixed mode (mode II dominant) conditions. The arrow shows the direction of crack propagation. The crack growth rate decreased as the crack length increased for these fatigue experiments, which were carried out under displacement control.

In Fig. $11 \mathrm{Ua}$, Ub, Uc and La, Lb, Lc are two sets of three different positions taken for the upper and lower adherends in the DCB specimen for pure mode I at $\Delta a$ of 9 , 12 and $20 \mathrm{~mm}$, respectively. The corresponding $\mathrm{da} / \mathrm{d} N$ and $\Delta G_{\text {Total }}$ are $8.38 \times 10^{-6}$, $2.34 \times 10^{-6}, 1.52 \times 10^{-7} \mathrm{~m} /$ cycles and $1135,1007,486 \mathrm{~J} / \mathrm{m}^{2}$, respectively, while in Fig. $12 \mathrm{Ua}, \mathrm{Ub}, \mathrm{Uc}$ and $\mathrm{La}, \mathrm{Lb}, \mathrm{Lc}$ are two sets of three different positions taken for the upper and lower adherends in DCB specimen for mode mixity of 6.62 at $\Delta a$ of 10,15 and $21 \mathrm{~mm}$, respectively. The corresponding $\log \mathrm{da} / \mathrm{d} N$ and $\Delta G_{\text {Total }}$ are $4.92 \times 10^{-6}$, $3.39 \times 10^{-6}, 1.12 \times 10^{-7} \mathrm{~m} /$ cycles and $1029,891,381 \mathrm{~J} / \mathrm{m}^{2}$. The values in the brackets 
are log values. The magnitude and range of crack growth rates for which the surfaces are shown are similar for both cases.

The fibrous features on the surfaces are assumed to be the polyester fibres in the adhesive carrier. The crack appears to grow in and around this carrier rather than remaining within the bulk of the adhesive layer. For the pure mode I test (Fig. 11), there appears to be a tendency for the slower crack growth rates to be associated with a rougher (more fibrous) appearance to the fracture surface. In particular at the higher crack growth rates, there is much less evidence of fibres suggesting the failure is more matrix dominated. In contrast, for the mixed mode test (Fig. 12) there is no clear change to the fracture surface morphology over the range of rates shown, which vary by a factor of more than 40 . Each image shows a similar fibrous morphology.

\subsection{Calculation of Fatigue Crack Propagation Parameters}

The aim of the current section is to formulate general crack growth relations of the form given in Eqs. 3 and 4. This follows an approach outlined by Blanco et al [29]. Other approaches could also be considered but this would require further investigation.

$$
\begin{aligned}
& \frac{d a}{d N}=C_{\mathrm{I}}\left(\Delta G_{\mathrm{I}}\right)^{m_{\mathrm{I}}} \\
& \frac{d a}{d N}=C_{\text {Total }}\left(\Delta G_{\text {Total }}\right)^{m_{\text {Toal }}}
\end{aligned}
$$

The values of $C_{\mathrm{I}}, m_{\mathrm{I}}$ and $C_{\text {Total }}, m_{\text {Total }}$ were found by curve fitting the experimental fatigue data using the plots of da/dNvs $\Delta G_{\mathrm{I}}$ and da/dNvs $\Delta G_{\text {Total }}$, respectively. In this curve fitting the entire data range was used as the aim of this was to develop a mixed mode FCG law that can be applied over a wide range of crack growth rates. It would be entirely possible to chose to use a different range of the data and this would lead to different values for the parameters. Fig. 13 shows the experimental variation of the Paris law coefficients $C_{\mathrm{I}}$ and $C_{\text {Total }}$ for FM73 with mode mixity as defined by the ratio $G_{I I} / G_{\text {Total }}$. Fig. 14 shows the experimental variation of the Paris 
law exponents $m_{\mathrm{I}}$ and $m_{\text {Total }}$ for FM73 with mode mixity as defined by the ratio $G_{\text {II }} / G_{\text {Total }}$.

The ratio of the mode II energy release rate to the total energy release rate, $G_{\text {II }} / G_{\text {Total }}$, is used as a measure of the mode mix. This ratio is preferred to the mode mix angle, $\psi$, because the dependence on $\psi$ becomes highly skewed as the mode I component approaches zero i.e. the pure mode II case [note $\psi=\tan ^{-1}\left(G_{I I} / G_{I}\right)$ and when $\left.G_{1}=0, \psi=\infty\right]$.

It is clear from Figs. 13 and 14 that the parameters vary non-monotonically with $G_{\text {II }} / G_{\text {Total }}$. Consequently, none of the monotonic models from the literature [22-28] are able to describe the variation of the experimental fatigue crack propagation parameters seen in FM73 adhesive. Hence, the use of a non-monotonic model to capture the variation of the propagation parameters is adopted here.

The parabolic expression proposed in [29] captures the dependence of the propagation parameters with the mode mix in this way. This model was applied to the current set of experiments and the parabolic fit to $C_{\mathrm{I}}, C_{\text {Total }}$ and $m_{\mathrm{I}}, m_{\text {Total }}$ are shown in Fig. 13 and 14 respectively for crack growth described by Eq. 3 and 4 . The expressions used for the parabolic fit are given by Eqs.5 and 6 below.

$$
\begin{gathered}
\log C=c_{1}+c_{2}\left(\frac{G_{\mathrm{II}}}{G_{\text {Total }}}\right)+c_{3}\left(\frac{G_{\mathrm{II}}}{G_{\text {Total }}}\right)^{2} \\
m=m_{1}+m_{2}\left(\frac{G_{\text {II }}}{G_{\text {Total }}}\right)+m_{3}\left(\frac{G_{\text {II }}}{G_{\text {Total }}}\right)^{2}
\end{gathered}
$$

The curve fit parameters, $c_{1}, c_{2}, c_{3}, m_{1}, m_{2}$ and $m_{3}$ are presented in Table 1 for crack growth based on $\Delta G_{\mathrm{I}}$ and $\Delta G_{\text {Total }}$.

Figs. 15 and 16 show the final results for the goodness of fit of the empirical formula to the experimental data for crack growth in FM73 adhesive based on $\Delta G_{I}$ and $\Delta G_{\text {Total, }}$ respectively. Not surprisingly, given the empirical nature of the approach, the trends of the data are captured well. The mode mix that best defines driving force may be material dependent (i.e., brittle systems are controlled by $G_{I}$ (or $\Delta G_{I}$ ) and tough systems by $G_{\text {Total }}$ (or $\Delta G_{\text {Total }}$ ) [30]. From a practical viewpoint, $\Delta G_{\text {Total }}$ (or $G_{\text {Total }}$ ) 
may be preferred since a model based purely on the mode I component cannot be applicable to the pure mode II loading.

\section{Concluding Remarks}

Crack growth in bonded joints under an extensive range of mixed mode fatigue loading has been studied using a loading jig developed specially for applying mixed mode loads to a DCB. Fatigue crack growth data for any particular geometry/test condition are reproducible and where there are discrepancies, these seem to be associated with the crack following an interfacial (as opposed to cohesive) crack path. The fatigue crack growth data have been shown to be consistent with other results published in the literature.

With regard to the details of the crack growth behaviour it appears that $\Delta G_{\text {Total }}$ correlates the range of mode mix propagation data much better than $\Delta G_{\mathrm{I}}$. However, even when correlating with total strain energy release rate range, the crack growth appears to be slightly lower when mode I dominates than when there is a larger mode II component. To accommodate this, generalised Paris laws have been formulated providing empirical relations for the crack growth rate as a function of the energy release rate range at any given mode mixity. It is shown that the parameters within this relation vary non-monotonically with the proportion of mode II present. The derived equations provide a good fit to the experimental data and, as such, these can provide accurate characterisation of the material to enable the fatigue crack growth rate in an arbitrary joint geometry to be modelled. From a practical viewpoint, characterisation on the basis of $\Delta G_{\text {Total }}$ is likely to be preferred.

\section{Acknowledgements}

The authors would like to thank Mr Peter Haynes and Mr Chris Burt for their help in material testing and scanning electron microscopy (SEM) respectively.

\section{References}


[1] T.A. Hafiz, M.M. Abdel Wahab, A.D. Crocombe and P.A. Smith, Mixed-mode fracture of adhesively bonded metallic joints under quasi-static loading, Eng Fract Mech, 77(2010), pp. 3434-3445.

[2] A. Pirondi and G. Nicoletto, Mixed mode I/II Fatigue crack growth in adhesive joints, Eng Fract Mech, 73 (16) (2006), pp. 2557-2568.

[3] A.J. Kinloch, Adhesion and adhesives: Science and technology, Chapman and Hall Ltd. (1987).

[4] S. Mostovoy and E.J. Ripling, Flaw tolerance of a number of commercial and experimental adhesives, Adhesion Science and Technology, Vol.9, Plenum Press, New York (1975), pp. 64-80.

[5] R.W. Hertzberg, Deformation and fracture mechanics of engineering materials (4th ed.), John Wiley \& Sons (1995).

[6] W. Elber, The significance of fatigue crack closure, ASTM STP 486, American Society for Testing and Materials, Philadelphia, PA, USA (1971).

[7] M. Fernando, W.W. Harjoprayitno and A.J. Kinloch, A fracture mechanics study of the influence of moisture on the fatigue behaviour of adhesively bonded aluminium joints, Int J Adhes Adhes 16 (1996), pp. 113-119.

[8] J.K. Jethwa and A.J. Kinloch, The fatigue and durability of automotive adhesives. Part I: fracture mechanics tests, J Adhesion 61 (1997), pp. 71-95.

[9] A.J. Kinloch, M.S.G. Little and J.F. Watts, The role of the interphase in the environmental failure of adhesive joints, Acta Mater 48 (2000), pp. 4543-4553.

[10] X.X. Xu, A.D. Crocombe and P.A. Smith, Frequency effect on fatigue crack growth rate in joints with either filled or filled and toughened adhesive, Int $J$ Fatigue, 17(4) (1995), pp. 279-286. 
[11] M. Dessureault and J.K. Spelt, Observations of fatigue crack initiation and propagation in an epoxy adhesive, Int $J$ Adhes Adhes 17 (1997), pp. 183-195.

[12] J.K. Shang, Interface crack growth in layered materials. In: G. Lutjering and H. Nowack, Editors, Fatigue '96, Pergamon (1996), pp. 43-53.

[13] J.G. Williams, On the calculation of energy release rate for cracked laminates. Int J Frac, 36 (1988), pp.101-119.

[14] T.A. Hafiz, Mixed-mode fracture in adhesively bonded joints under quasi-static and fatigue loading, PhD thesis, University of Surrey, UK.

[15] A. Pirondi and G. Nicoletto, Fatigue crack growth in bonded DCB specimens, Eng Fract Mech, 71(2004), pp. 859-871.

[16] User manual, Instron 8511.

[17] I.A. Ashcroft, D.J. Hughes and S.J. Shaw, Mode I fracture of epoxy bonded composite joints: Part1. Quasi-static loading, Int J Adhes Adhes, 21 (2001), pp. 8799.

[18] R.W. Hertzberg and J.A. Manson, Fatigue of engineering plastics, Academic press, New York (1980).

[19] E.J. Ripling, P.B. Crosley and W.S. Johnson, A comparison of pure mode I and mixed mode I-III cracking of an adhesive containing an open knit cloth carrier adhesively bonded joints: Testing, Analysis and Design, ASTM STP 981, WS Johnson,Ed., ASTM, Philadelphia (1988), pp. 163-182.

[20] W.S. Johnson, M.B. Lawrence and V.V. Rodolfo, Application of fracture mechanics to the durability of bonded composite joints" Report No. DOT/FAA/AR97/56, 1998.

[21] V. Shenoy, I.A. Ashcroft, G.W. Critchlow and A.D. Crocombe, Fracture mechanics and damage mechanics based fatigue lifetime prediction of adhesively bonded joints subjected to variable amplitude fatigue, Eng Fract Mech, 77 (2010), pp. 073-1090. 
[22] R.L. Ramkumar and J.D. Whitcomb, Characterization of mode I and mixedmode delamination growth in T300/5208 graphite/epoxy. In: Delamination and Debonding of MaterialsASTM STP 876, American Society for Testing and Materials, Philadelphia (1985), pp. 315-335.

[23] C.G. Gustafson and M. Hojo, Delamination fatigue crack growth in unidirectional graphite/epoxy laminates. J Reinf Plast Comp, 6 (1987), pp. 36-52.

[24] A.J. Russell and K.N. Street, Predicting interlaminar fatigue crack growth rates in compressively loaded laminates. In: Delamination and Debonding of MaterialsASTM STP 1012, American Society for Testing and Materials, Philadelphia (1989), pp. 162-178.

[25] C. Dahlem and G.S. Springer, Delamination growth in composites under cyclic loads, J Comp Mater, 28(1994), pp. 732-781

[26] G.A. Kardomateas, A.A. Pelegri and B. Malik, Growth of internal delaminations under cyclic compression in composite plates, J Mech Phy Sol, 43 (1995), pp. 847868.

[27] M. Kenane and M.L. Benzeggagh, Mixed-mode delamination fracture toughness of unidirectional glass/epoxy composites under fatigue loading, Comp Sci Technol, 57 (1997), pp. 597-605

[28] J. Andersons, M. Hojo and S. Ochiai, Model of delamination propagation in brittle-matrix composites under cyclic loading, J Reinf Plas Comp, 20 (2001), pp. $431-450$

[29] N. Blanco, E.K. Gamstedt, L.E. Asp and J. Costa, Mixed-mode delamination growth in carbon-fibre composite laminates under cyclic loading, Int J Sol Struc, 41(2004), pp. 4219-4235.

[30] W.S. Johnson and P.D. Mangalgiri, Influence of the resin on interlaminar mixedmode fracture, Toughened Composites, Johnston NJ ed., ASTM STP Philadelphia, 937 (1987), pp. 295-315. 

Figures:

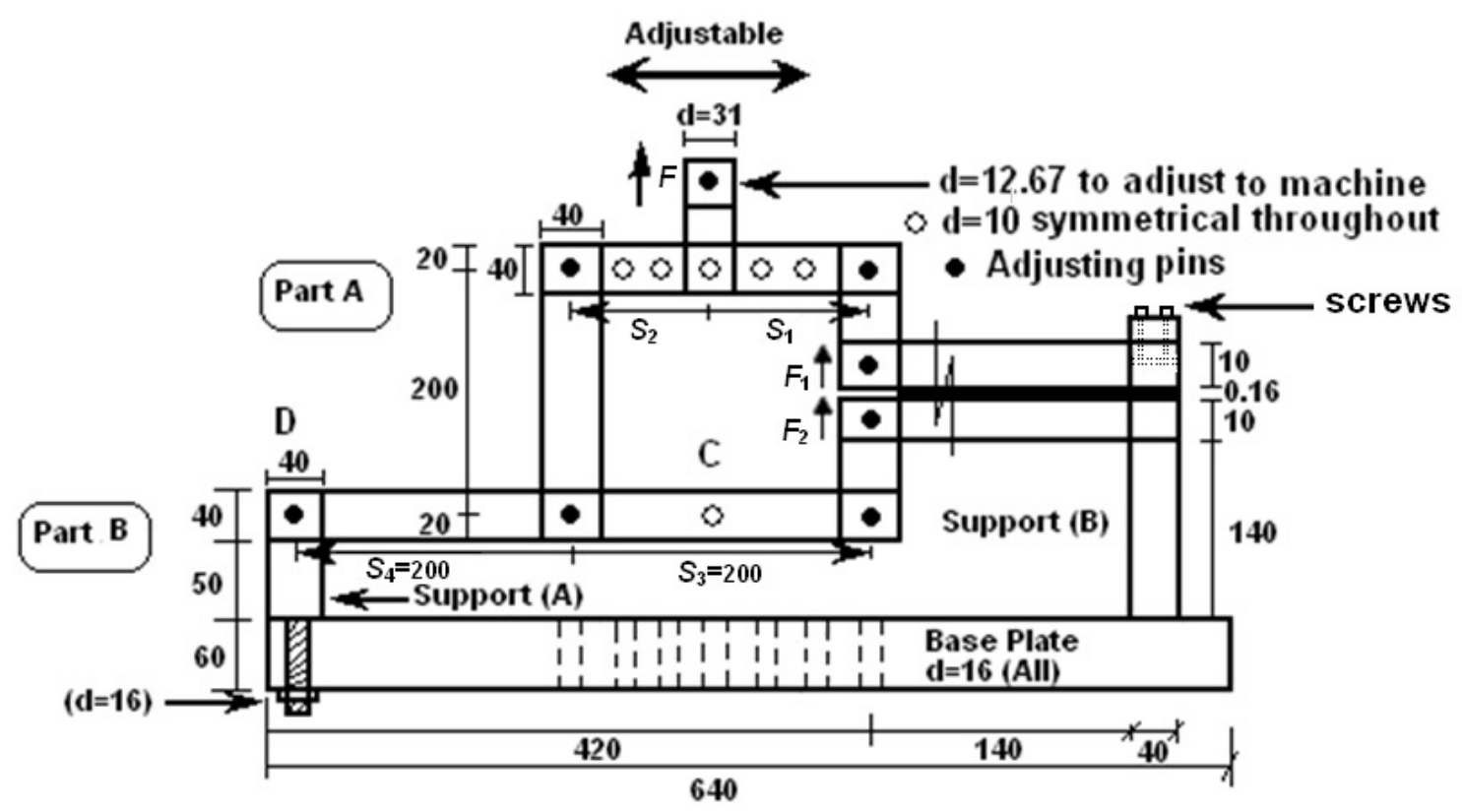

Figure 1 Schematic Diagram of the Load Jig (all dimensions in $\mathrm{mm}$ )

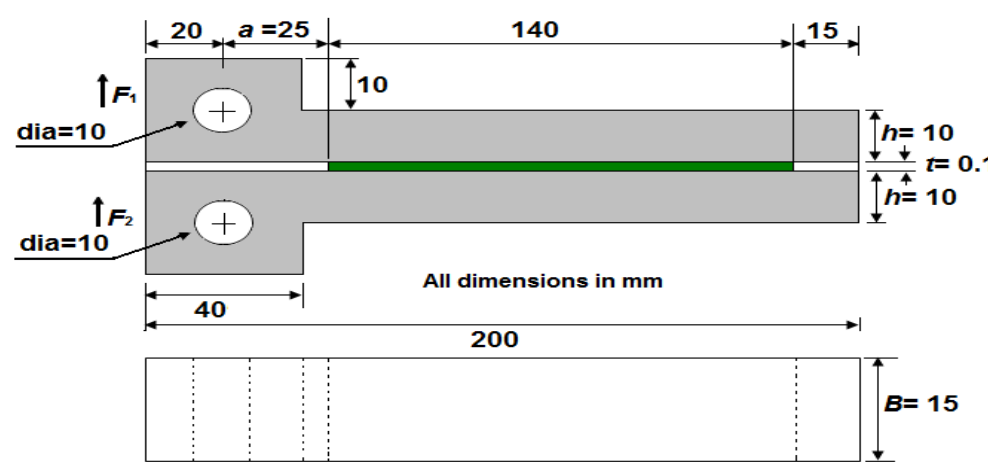

Metallic Adherend FM 73 Adhesive Shim

$M_{1}=F_{1} a$

$M_{2}=F_{2} a$

$M_{1}=\left(M_{1}-M_{2}\right) / 2$

$M_{11}=\left(M_{1}+M_{2}\right) / 2$

$\lambda_{b}^{4}=\frac{6 E_{\mathrm{a}}}{h^{3} t E}$

$G_{1}=\frac{12 M_{1}^{2}}{B^{2} E h^{3}}\left(1+\frac{(1+u)}{5}\left(\frac{h}{a}\right)^{2}\right)\left(1+\frac{1}{\lambda_{\sigma} a}\right)^{2}$

$G_{11}=\frac{9 M_{ע}^{2}}{B^{2} E h^{3}}\left(1+\frac{1}{\lambda_{\sigma} a}\right)^{2}$

$\lambda_{t}$ serves as length scale for the crack problem $E_{\text {a }}$ Young's modulus of the adhesive

$E$ Young's modulus of the metallic adherend

$u$ Poisson's ratio

Figure 2 Bonded DCB specimen geometry 


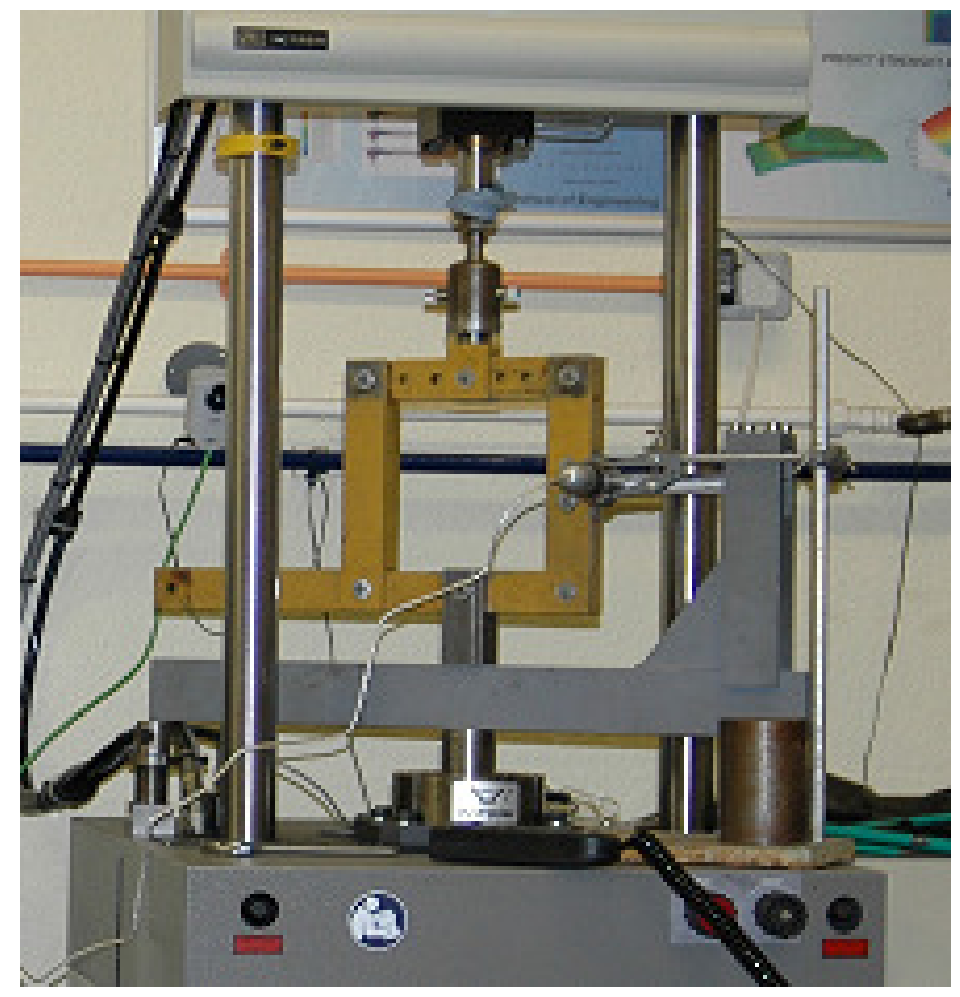

Figure 3 Experimental set-up

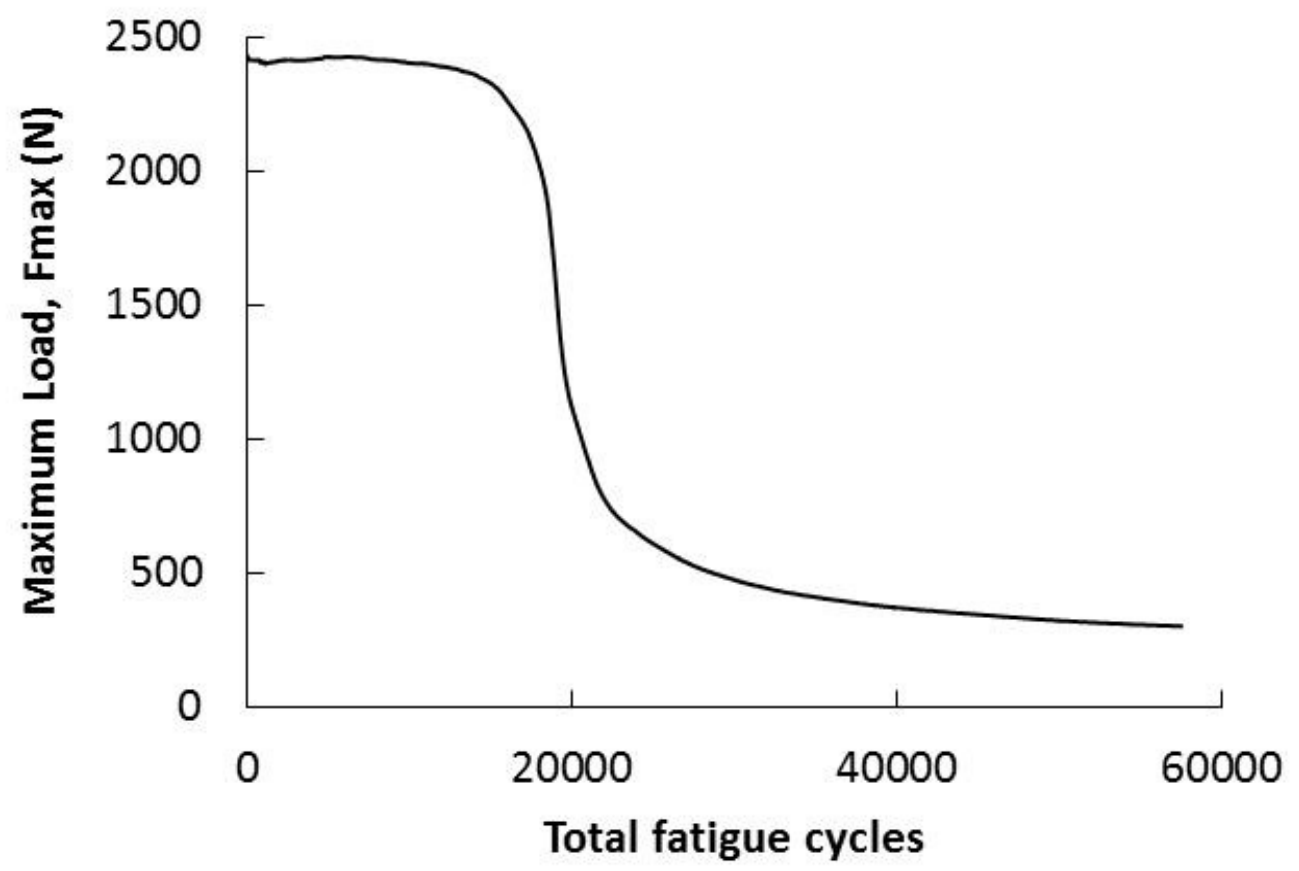


Figure 4 Variation in maximum load with total number of fatigue cycles for a specimen with an initial mode mixity $G_{I I} / G_{I}=0.72$

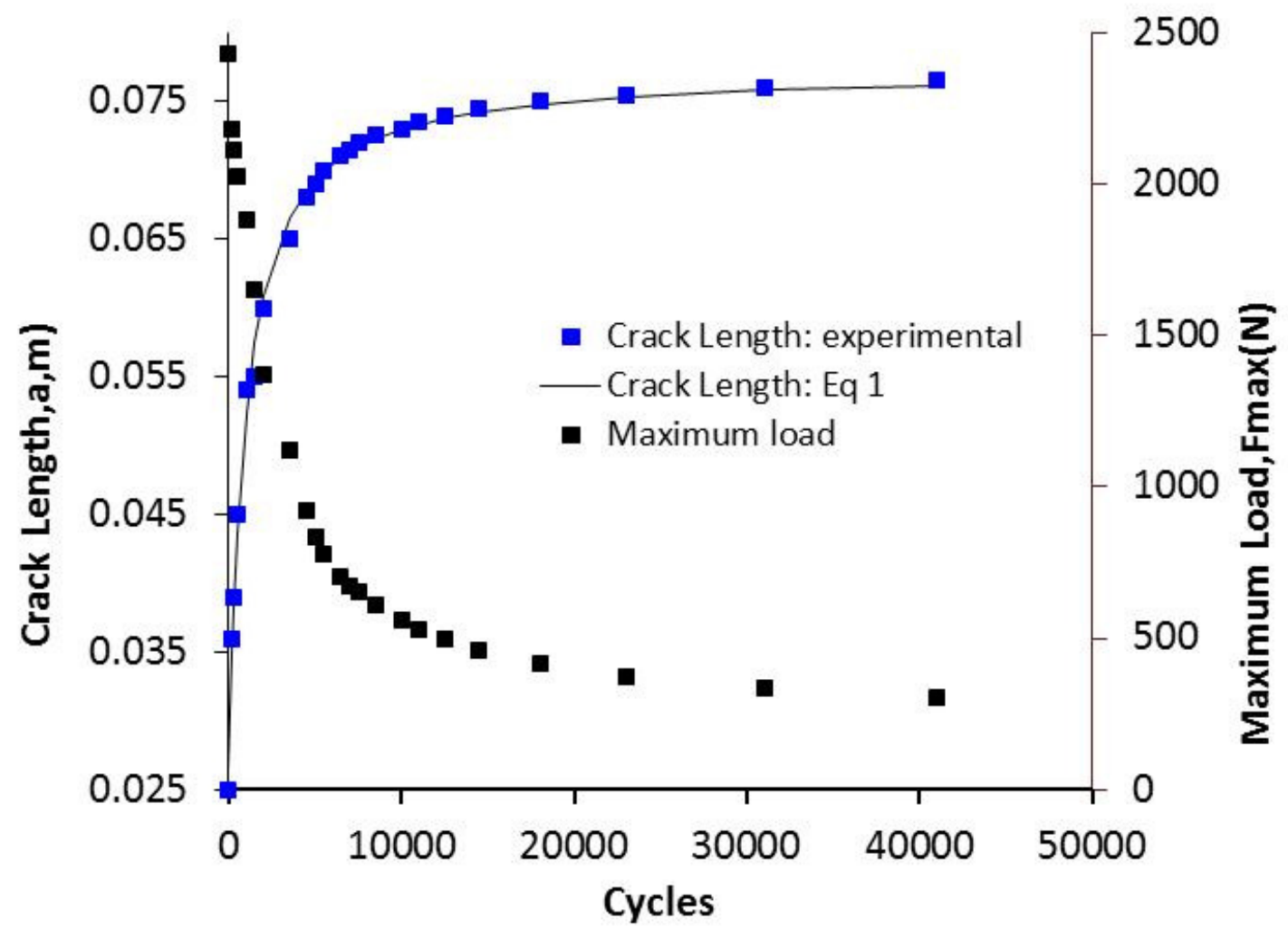

Figure 5 Variation in load and crack length with number of fatigue cycles $(M)$ following onset of crack growth in a mixed mode specimen mixity $G_{I I} / G_{I}=0.72$

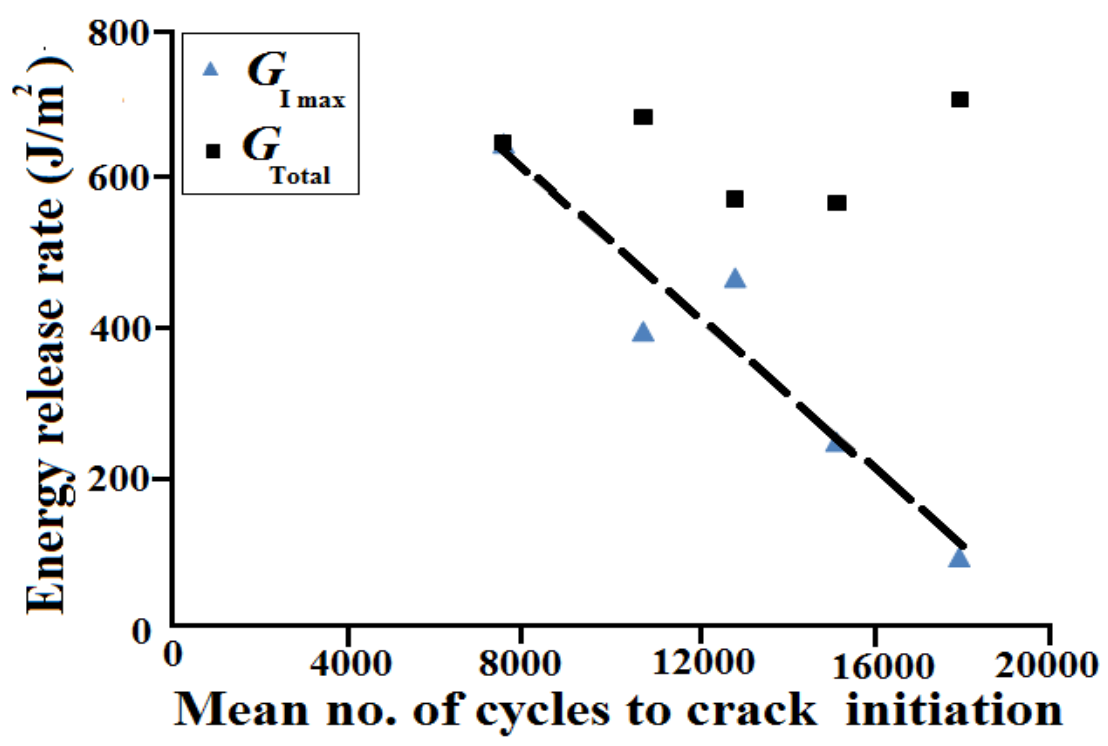


Figure 6 Plot of strain energy release rate against number of cycles to crack initiation (averaged for each mode mix) in various bonded joint geometries subject to fatigue at an initial load level corresponding to $70 \%$ of the quasi-static strength.

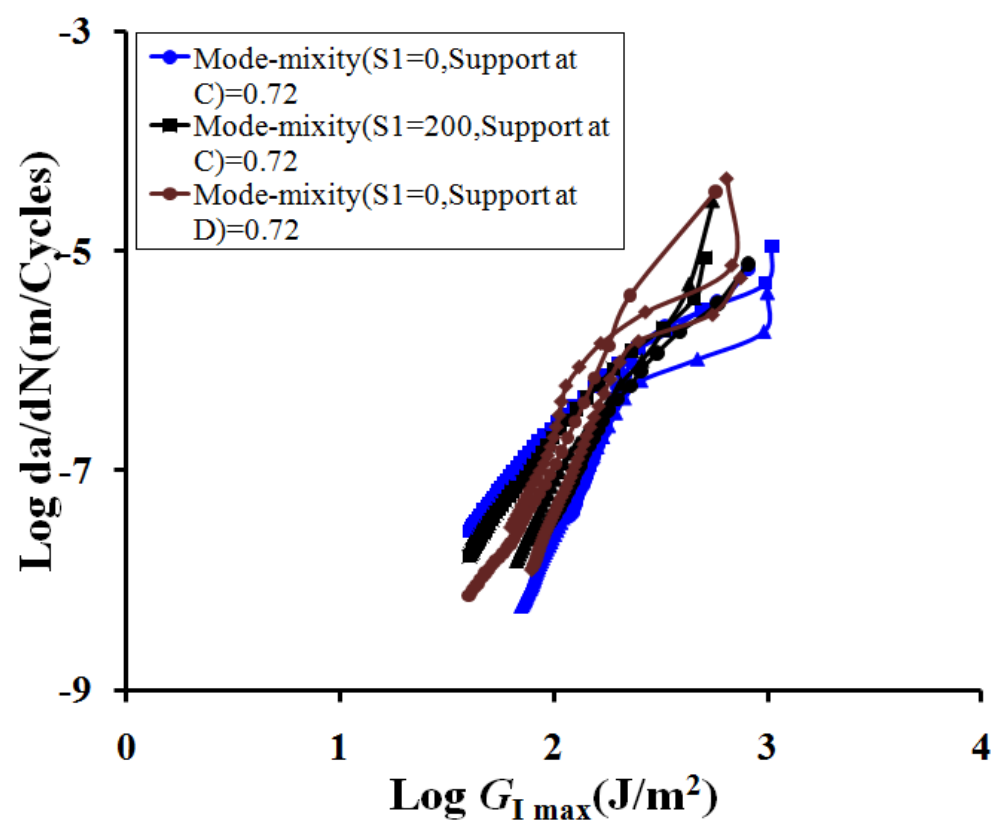

Figure 7 Fatigue crack growth data for all test configurations providing a mode mixity of $\mathbf{0 . 7 2}$ 


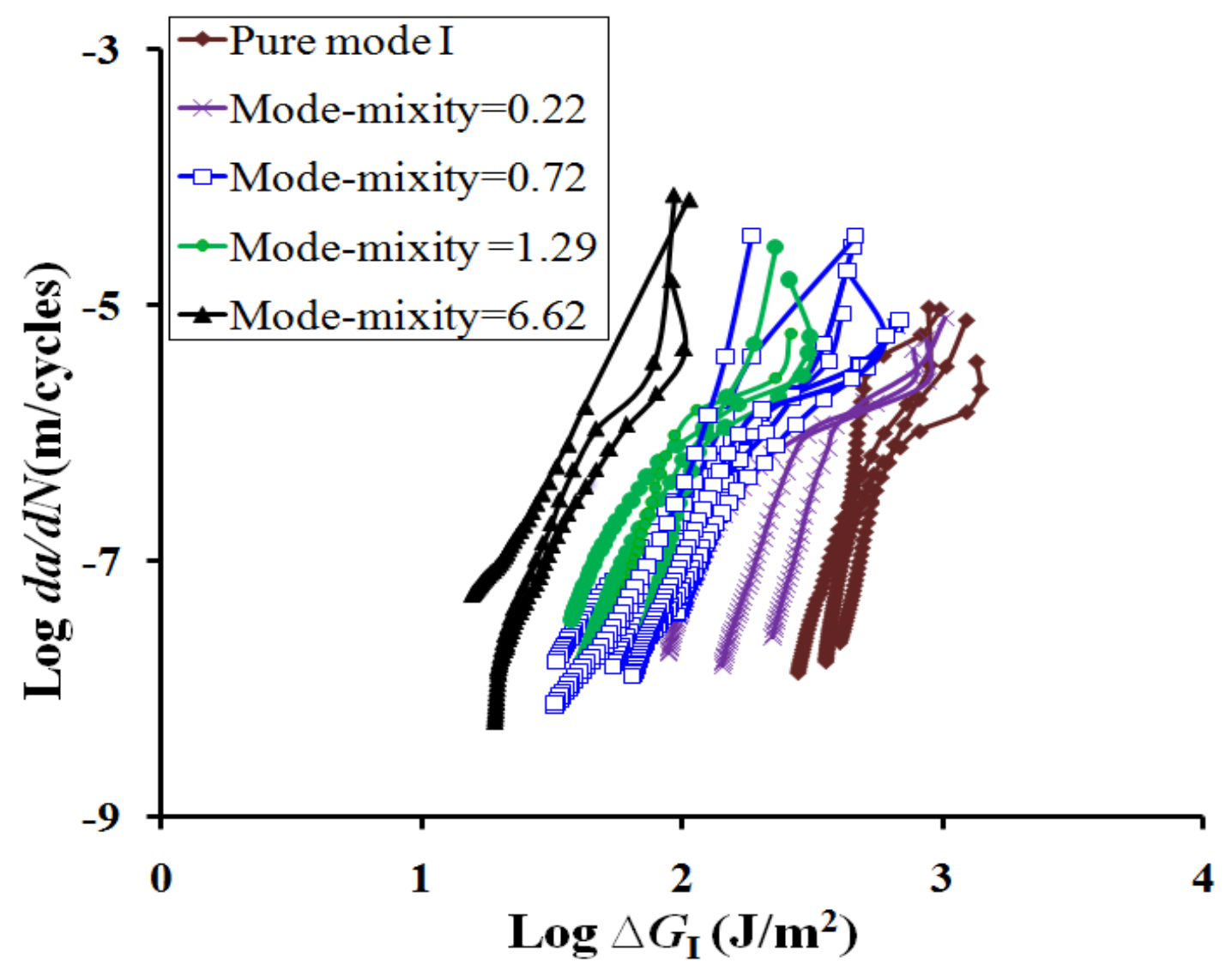

Figure 8 Plot of log (crack growth rate) against $\log \Delta G_{I}$ for the range of mode mixity values used in the present study 


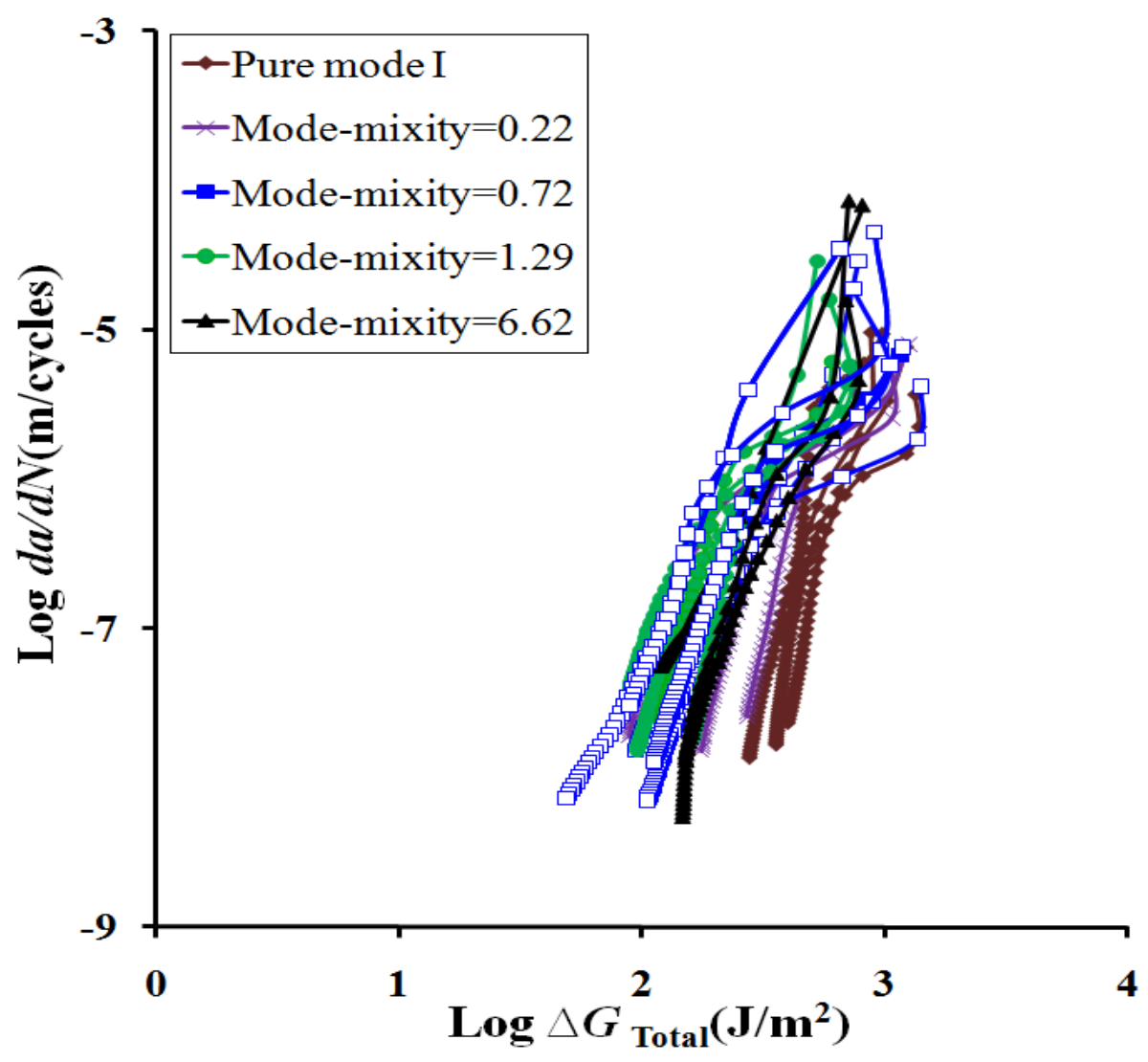

Figure 9 Plot of $\log$ (crack growth rate) against $\log \Delta \mathbf{G}_{\text {Total }}$ for the range of mode mixity values used in the current study. 


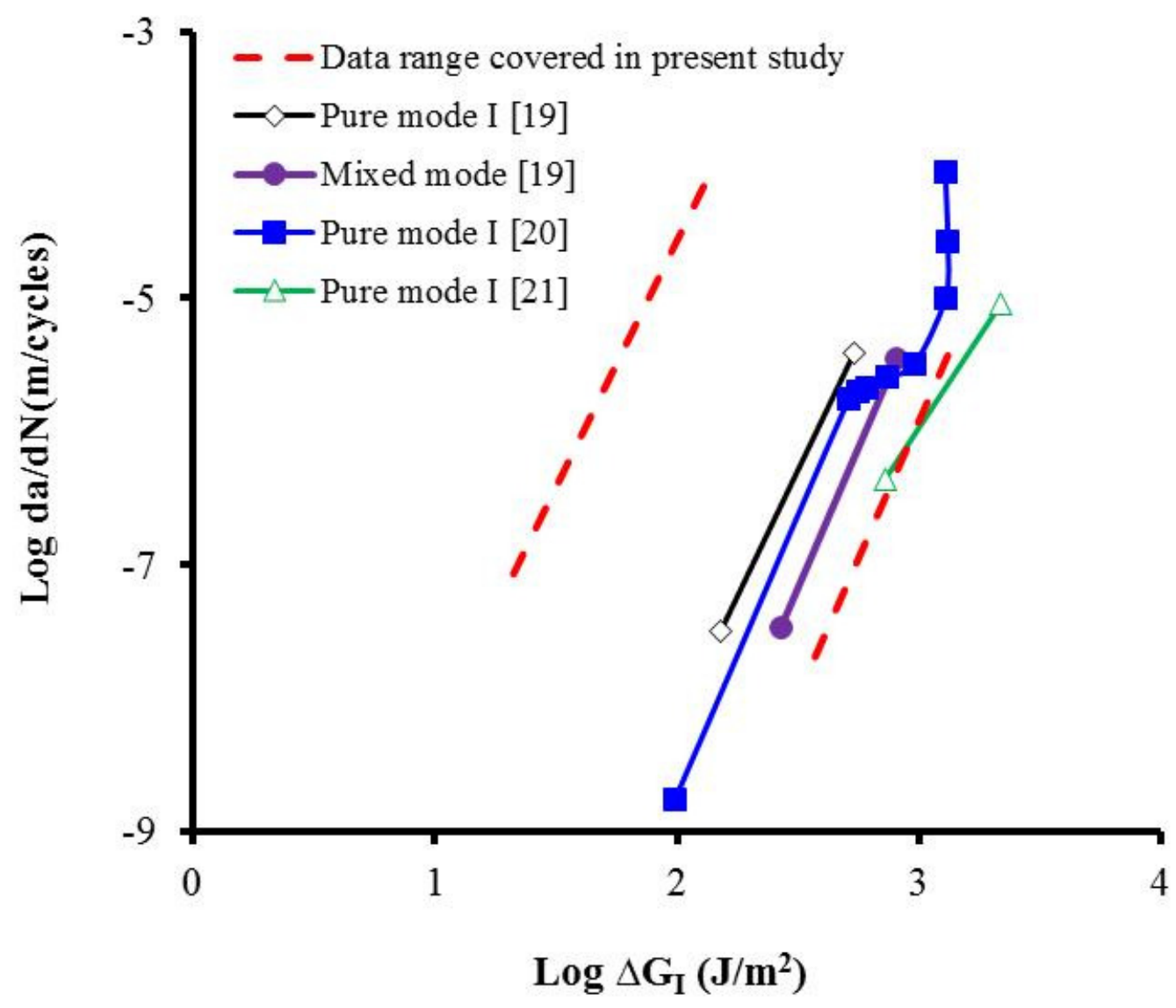

Figure 10 Comparison of plot of log (crack growth rate) against $\log \Delta \mathbf{G}_{\mathrm{I}}$ with range of values in the literature 


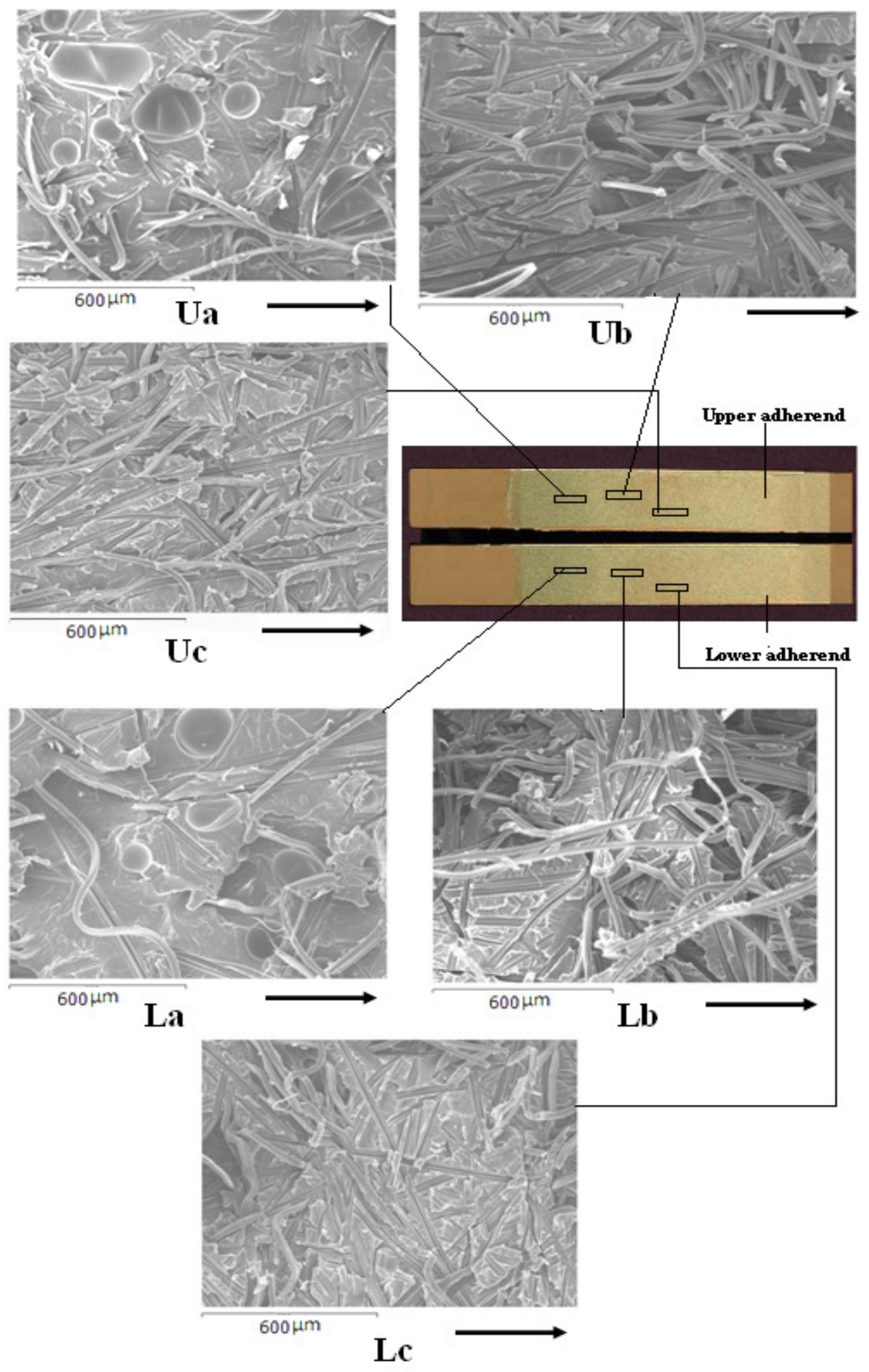

Figure 11 SEM images of the fracture surface of pure mode I fatigue specimen 


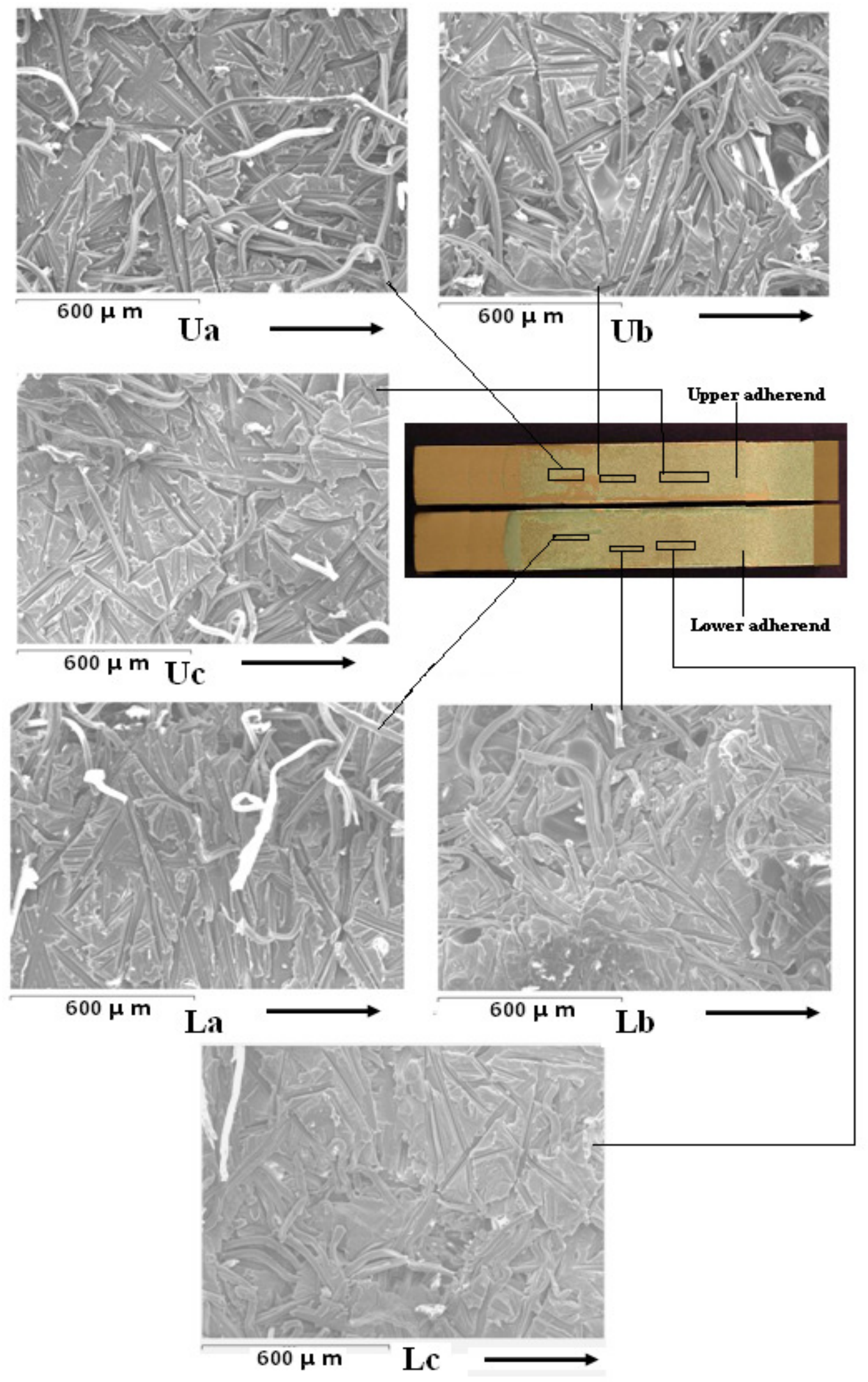

Figure $12 \mathrm{SEM}$ image of the fracture surface for an initial mode mixity ratio, $G_{\mathrm{II}} / G_{\mathrm{I}}=6.62$, fatigue specimen 


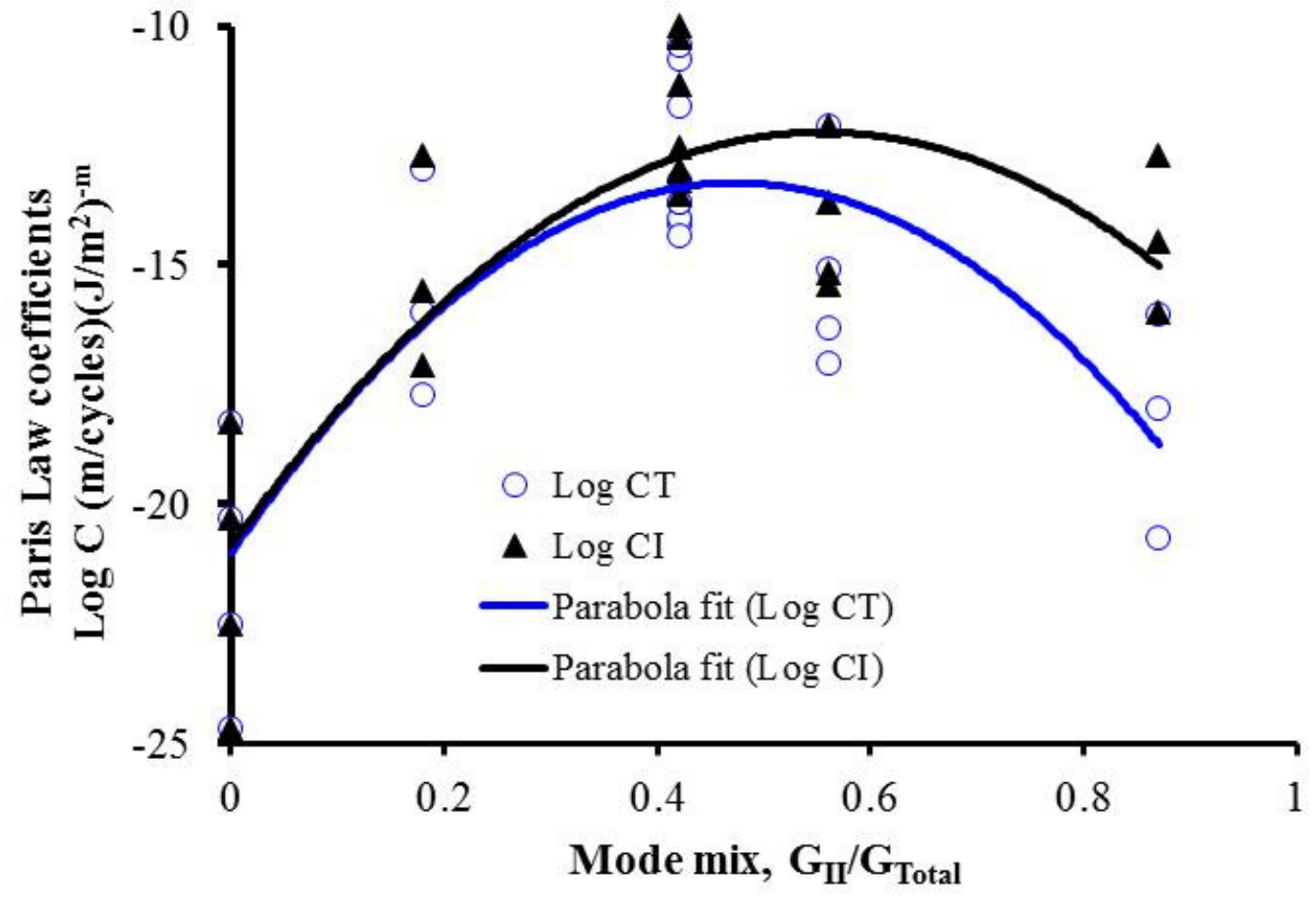

Figure 13 Variation of fatigue crack propagation coefficient for FM73 adhesive under different mode mixities based on $\Delta \boldsymbol{G}_{\mathrm{I}}$ and $\Delta \boldsymbol{G}_{\mathrm{Total}}$ energy release rates 


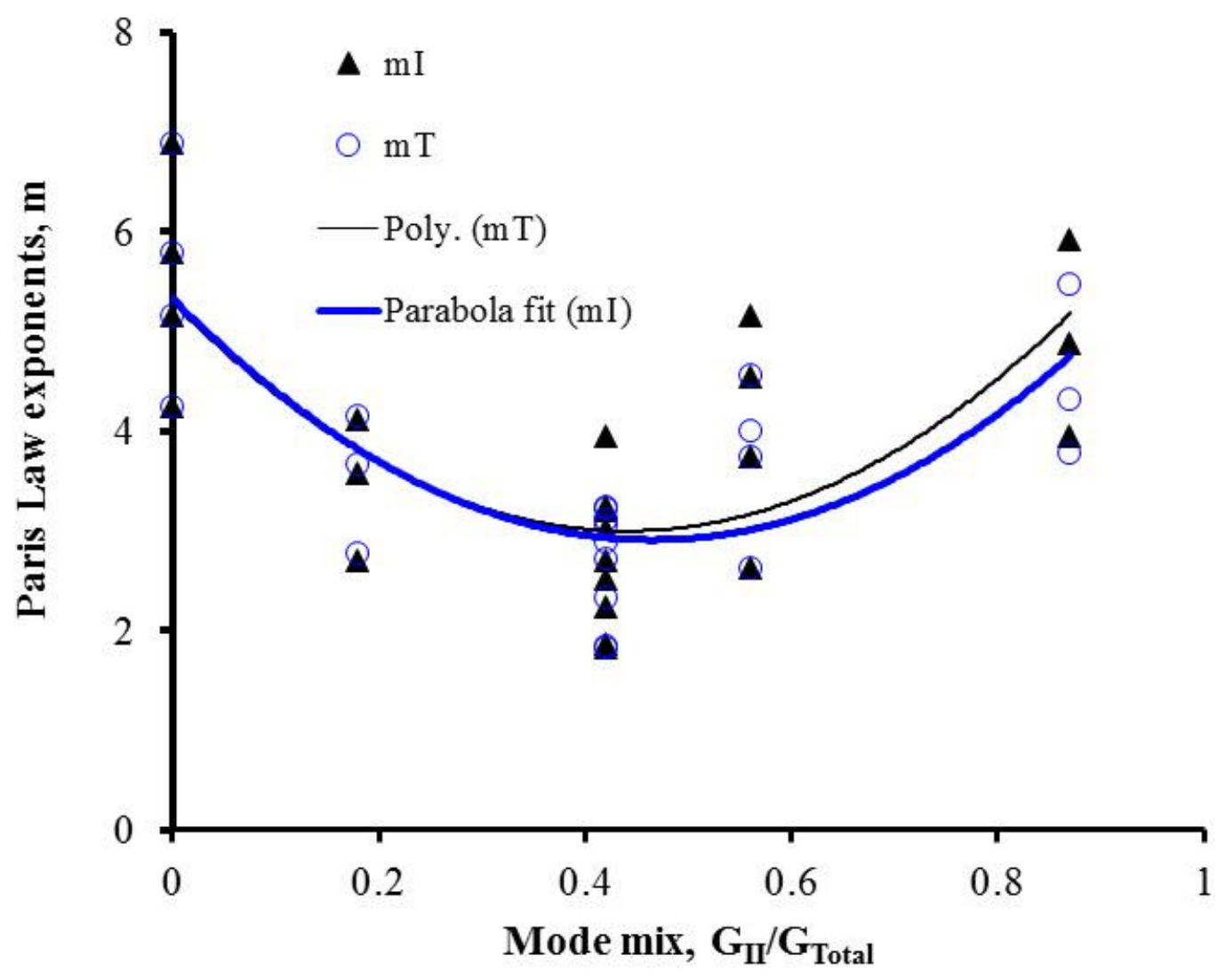

Figure 14 Variation of fatigue crack propagation exponent for FM73 adhesive under different mode mixities based on $\Delta G_{\mathrm{I}}$ and $\Delta G_{\text {Total }}$ energy release rates. 


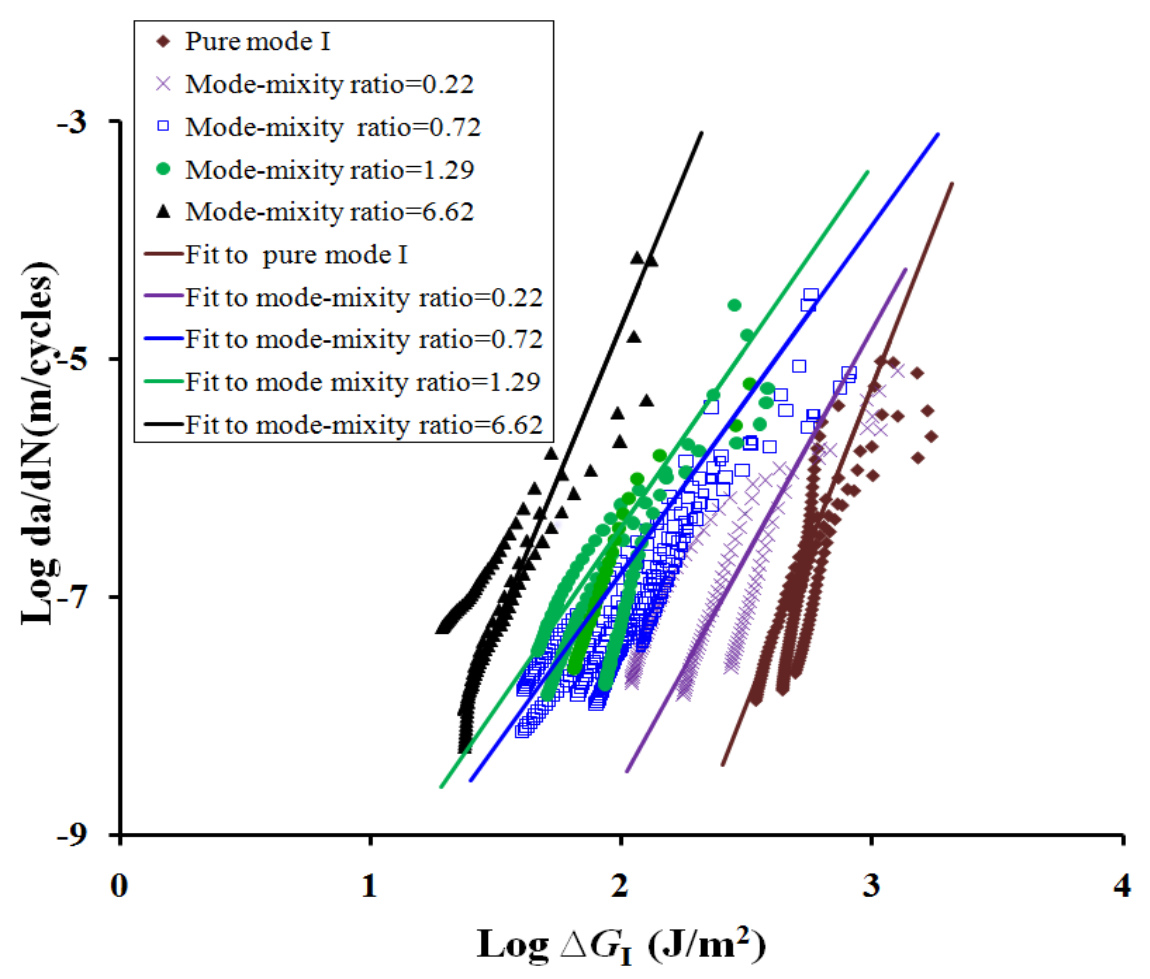

Figure 15 Goodness of fit of the empirical formula on the experimental data for FM73 adhesive under different mode mixities based on $\Delta G_{I}$ energy release rate.

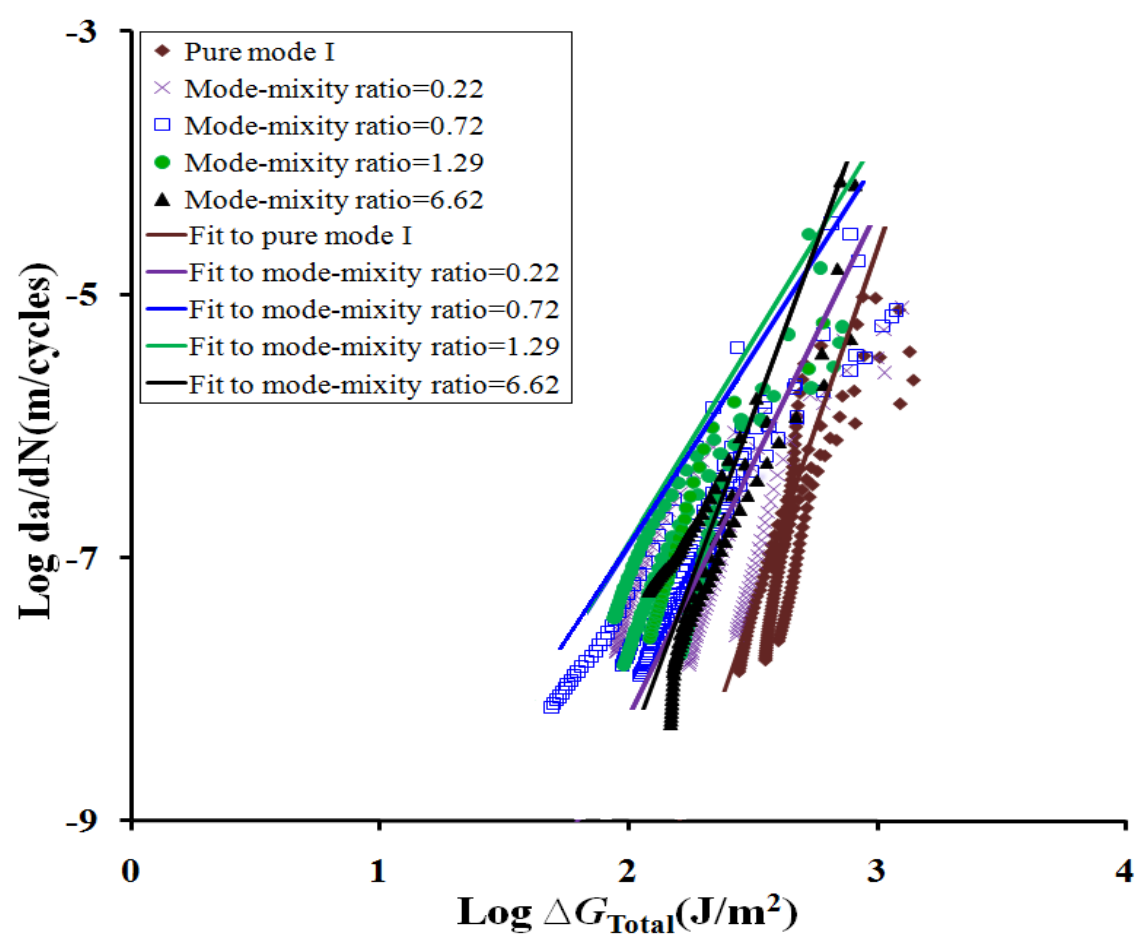

Figure 16 Goodness of fit of the empirical formula on the experimental data for FM73 adhesive under different mode mixities based on $\Delta \boldsymbol{G}_{\mathrm{Total}}$ energy release rate. 
Tables:

Table 1 Polynomial coefficients for fatigue crack growth in FM73 adhesive at different modemixities determined by a curve fitting based on $\Delta \boldsymbol{G}_{\mathrm{I}}$ and $\Delta \boldsymbol{G}_{\mathrm{Total}}$ energy release rates.

\begin{tabular}{|c|c|c|}
\hline Curve fit parameters & Values based on $\Delta G_{\mathrm{I}}$ & Values based on $\Delta G_{\text {Total }}$ \\
\hline$c_{1}$ & -20.87 & -21.03 \\
\hline$c_{2}$ & 31.17 & 32.77 \\
\hline$c_{3}$ & -28.10 & -34.65 \\
\hline$m_{1}$ & 5.34 & 5.33 \\
\hline$m_{2}$ & -10.74 & -10.44 \\
\hline$m_{3}$ & 11.86 & 11.23 \\
\hline
\end{tabular}

